\title{
Características fermentativas de silagens de capim-elefante emurchecido ou com adição de farelo de cacau
}

[Fermentation characteristics of silage of elephantgrass wilted or with addition of cocoa meal]

\author{
G.G.P. Carvalho ${ }^{1,4}$, R. Garcia ${ }^{2,4}$, A.J.V. Pires ${ }^{3,4}$, O.G. Pereira ${ }^{2,4}$, F.E.P. Fernandes ${ }^{1,5}$, B.M.A. Carvalho ${ }^{1}$ \\ ${ }^{1}$ Aluno de pós-graduação UFV \\ ${ }^{2}$ Departamento de Zootecnica - UFV \\ Av. P.H. Rolfs, s/n \\ 36571-000 - Viçosa, MG \\ ${ }^{3}$ Universidade Estadual do Sudoeste da Bahia - Itapetinga, BA. \\ ${ }^{4}$ Bolsista do CNPq \\ ${ }^{5}$ Bolsista da CAPES
}

\begin{abstract}
RESUMO
O experimento foi realizado para avaliar as características fermentativas da silagem de capim-elefante emurchecido ou adicionado de diferentes níveis de farelo de cacau. O capim-elefante utilizado foi colhido aos 50 dias de rebrota após o corte de uniformização e submetido aos seguintes tratamentos na ensilagem: capimelefante emurchecido ao sol por oito horas e capim-elefante sem emurchecimento adicionado de 0, 7, 14, 21 e $28 \%$ de farelo de cacau (\% da matéria natural). Foram utilizadas quatro repetições por tratamento. O material foi acondicionado em silos de PVC com $0,15 \mathrm{~m}$ de diâmetro e $0,3 \mathrm{~m}$ de altura, adotando-se compactação de $500 \mathrm{~kg} / \mathrm{m}^{3}$. O pH reduziu e os carboidratos solúveis $\left(\mathrm{CHO}_{\mathrm{S}}\right)$ aumentaram de forma linear $(\mathrm{P}<0,05)$ com a adição de farelo de cacau. $\mathrm{O}$ teor de $\mathrm{N}_{-} \mathrm{NH}_{3}$ aumentou com a adição de farelo de cacau na ensilagem, contudo, os teores dos ácidos orgânicos não diferiram entre a silagem com farelo de cacau e aquela com capim-elefante emurchecido. A inclusão de $0,7,14,21$ e $28 \%$ de farelo de cacau provocou aumentos de 2,23; 2,48; 3,14; 3,49 e $3,47 \%$ no teor de ácido lático, respectivamente. A qualidade fermentativa da silagem de capim-elefante melhorou com a adição de farelo de cacau.
\end{abstract}

Palavras-chave: forrageira, Pennisetum purpureum, subproduto, Theobroma cacao, fermentação, ácido orgânico

\section{ABSTRACT}

The experiment was carried out to evaluate the fermentation characteristics of eight hours sun light wilted elephant grass silage in comparison to no sun light exposed silage added by 0, 7, 14, 21, and 28\% of cocoa meal during the ensilage process. PVC silos, measuring $0.15 \mathrm{~m}$ diameter $\times 0.30 \mathrm{~m}$ height, were used to ensilage the elephantgrass using a compacting pressure of $500 \mathrm{~kg} / \mathrm{m}^{3}$. Soluble carbohydrates decreased but $\mathrm{pH}$ and $\mathrm{N}$ NH3 increased $(P<0.05)$ as the cocoa meal level increased in the silage. No difference between wilted and no wilted elephantgrass silages was observed for organic acid content. Addition of 0, 7, 14, 21, and 28\% of cocoa meal caused an increase of 2.23, 2.48, 3.14, 3.49, and 3.87\% of lactic acid contents. Addition of cocoa meal during the ensilage process enhanced fermentation quality of elephantgrass silage.

Keywords: roughage, Pennisetum purpureum, by-product, Theobroma cacao, fermentation, organic acids

\section{INTRODUÇ̃̃O}

Originário da África, o capim-elefante (Pennisetum purpureum, Schum.) é uma das forrageiras com maior potencial para utilização na forma de silagem, principalmente por sua alta produção de matéria seca (MS) e pelo equilíbrio de nutrientes quando jovem, o que estimula seu cultivo em todo o Brasil (Lopes et al., 2000; Queiroz Filho et al., 2000). Entretanto, a presença de alto teor de umidade no momento ideal para o corte e o baixo teor de carboidratos

Recebido em 7 de junho de 2006

Aceito em 17 de dezembro de 2007

E-mail: gleidsongiordano@gmail.com 
solúveis na maioria das gramíneas forrageiras são fatores que inibem o adequado processo fermentativo e dificultam a produção de silagens de boa qualidade (Ferrari Júnior e Lavezzo, 2001).

A conservação de determinada forrageira como silagem envolve um complexo processo bioquímico e microbiológico, desde a colheita até sua utilização na alimentação animal. A forrageira ensilada é conservada por produtos originados da fermentação anaeróbica e, normalmente, os critérios utilizados para classificação de silagens abrangem os valores de $\mathrm{pH}$, os ácidos orgânicos e o nitrogênio amoniacal (Vilela, 1998).

Silagens produzidas com forrageiras com baixo teor de MS desencadeiam perdas por efluente e propiciam o desenvolvimento de bactérias do gênero Clostridium, em virtude do excesso de umidade da forragem. O desenvolvimento dessas bactérias produz fermentações secundárias indesejáveis e promove a formação de ácido butírico, o que caracteriza silagens de baixa qualidade, ocorrendo, concomitantemente, degradação de proteína e de ácido lático (McDonald et al., 1991).

Outro fator que afeta a produção de silagem de boa qualidade é o teor de carboidratos solúveis, pois capins tropicais, além de conterem elevado teor de umidade, normalmente são pobres em carboidratos solúveis (menos de 5\%), características desfavoráveis à ensilagem. $\mathrm{O}$ teor de carboidratos solúveis das forrageiras durante a ensilagem é importante para que o processo fermentativo se desenvolva de modo eficiente (McDonald et al., 1991). O desenvolvimento de bactérias desejáveis no interior do silo, sobretudo as láticas, depende essencialmente da presença de carboidratos solúveis. Com a adequada produção de ácido lático e a rápida redução do potencial hidrogeniônico $(\mathrm{pH})$, são estabelecidas condições necessárias para inibição da atividade proteolítica das enzimas vegetais e da proliferação das bactérias indesejáveis (Muck, 1988).

O excesso de umidade da forragem para produção de silagem, quando a planta tem alto valor nutritivo, tem merecido a atenção de pesquisadores. Diversos trabalhos têm sido realizados com o propósito de avaliar alternativas que possam beneficiar o processo fermentativo de silagens de capim-elefante, como a adição de alimentos ricos em carboidratos (Rodrigues et al., 2005), de inoculantes enzimobacterianos (Henrique e Bose, 1992), de produtos com elevados teores de MS (Bernardino et al., 2005) e de substâncias nitrogenadas (Singh e Pandita, 1984), além do pré-emurchecimento (Ferrari Júnior e Lavezzo, 2001).

Segundo Silva et al. (2006), a produção brasileira de farelo de cacau em 2000 foi de, aproximadamente, 20.000t. Considerando a disponibilidade desse subproduto agrícola (o farelo representa $10 \%$ da produção das amêndoas secas de cacau) nas regiões produtoras, seus teores de MS $(86,1 \%)$ e PB $(13,6 \%)$ e suas propriedades higroscópicas, o farelo de cacau pode atuar como potencial aditivo se adicionado ao capim-elefante no momento da ensilagem, por promover acréscimo no teor de MS e possibilitar, portanto, a obtenção de silagens de boa característica fermentativa.

Desse modo, realizou-se um experimento para avaliar as características fermentativas da silagem de capim-elefante (Pennisetum purpureum, Schum. cv. Napier) pré-emurchecido ou com adição de diferentes níveis de farelo de cacau (Theobroma cacao L.).

\section{MATERIAL E MÉTODOS}

O capim-elefante utilizado foi proveniente de uma capineira estabelecida em um solo classificado do tipo chernossolo argilúvio, ótico, típico, estruturado hipereutrófico, com textura argilosa, fase floresta subcaducifólia e relevo ondulado (Sistema..., 1999).

O capim foi submetido a um corte de uniformização a $10 \mathrm{~cm}$ do solo e, após 50 dias de rebrota, foi colhido manualmente a $10 \mathrm{~cm}$ do solo, picado em ensiladeira estacionária (tamanho médio de partícula de $2 \mathrm{~cm}$ ) e submetido aos seguintes tratamentos para ensilagem: A - capim-elefante emurchecido ao sol por 8 horas; B - capim-elefante nãoemurchecido; C - capim-elefante + farelo de cacau (7\%); D - capim-elefante + farelo de cacau (14\%); E - capim-elefante + farelo de cacau $(21 \%) ; \mathrm{F}$ - capim-elefante + farelo de cacau $(28 \%)$. 
Para obtenção da silagem de capim-elefante emurchecido (tratamento A), o capim foi colhido, espalhado no campo e, após oito horas de exposição ao sol, foi picado e ensilado. Nas silagens produzidas com farelo de cacau, o capim foi cortado e triturado em ensiladeira estacionária, sem nenhum emurchecimento prévio, e imediatamente adicionado do farelo de cacau, com base na matéria natural (peso/peso).

O material foi ensilado em silos experimentais de PVC, cilíndricos $(0,15 \mathrm{~m}$ de diâmetro e $0,3 \mathrm{~m}$ de altura), por meio de compactação manual, em densidade de $500 \mathrm{~kg} / \mathrm{m}^{3}$, correspondente a $2,65 \mathrm{~kg}$ de matéria natural por silo. Em seguida, foram vedados com lona plástica nas duas extremidades, com auxílio de arame liso galvanizado e fita plástica, e armazenados em galpão coberto durante 45 dias. Após esse período, os silos foram abertos para a coleta de amostras, as quais foram congeladas para posteriores análises.

A composição química do capim-elefante emurchecido e não-emurchecido e do farelo de cacau (Tab. 1) foi determinada segundo metodologia descrita por Silva e Queiroz (2002).

Tabela 1. Teores médios de matéria seca (MS), proteína bruta (PB), extrato etéreo (EE), fibra em detergente neutro $(\mathrm{FDN})$, fibra em detergente neutro corrigida para cinzas e proteína $\left(\mathrm{FDN} \mathrm{CP}_{\mathrm{C}}\right)$, fibra em detergente ácido (FDA), cinzas, celulose, hemicelulose, carboidratos totais (CHO), carboidratos nãofibrosos (CNF), carboidratos solúveis (CHOs), $\mathrm{pH}$ e digestibilidade in vitro da matéria seca (DIVMS) do capim-elefante e do farelo de cacau

\begin{tabular}{lrrr}
\hline Item & \multicolumn{2}{c}{ Capim-elefante } & \\
\cline { 2 - 3 } & Não-emurchecido & Emurchecido & Farelo de cacau \\
\hline MS & 20,1 & 27,8 & 89,8 \\
PB $^{1}$ & 8,6 & 8,5 & 13,5 \\
EE $^{1}$ & 1,7 & 1,8 & 9,9 \\
FDN $^{1}$ & 71,1 & 68,6 & 48,5 \\
FDN $_{\text {CP }}$ FDA $^{1}$ & 67,5 & 65,2 & 43,6 \\
Cinza $^{1}$ & 43,6 & 41,3 & 40,0 \\
Celulose $^{1}$ & 9,6 & 9,8 & 7,4 \\
Hemicelulose $^{1}$ & 40,3 & 37,9 & 23,1 \\
CHO $^{1}$ & 27,4 & 27,3 & 8,5 \\
CNF $^{1}$ & 80,1 & 79,9 & 69,2 \\
CHOs $^{1}$ & 12,6 & 14,4 & 25,7 \\
pH $^{\text {DIVMS }}{ }^{1}$ & 10,9 & 10,2 & 12,2 \\
\hline
\end{tabular}

$1 \%$ da MS.

Os carboidratos solúveis foram extraídos por fervura em água e estimados por colorimetria, segundo Deriaz (1961), descrito por Silva e Queiroz (2002).

Parte da silagem in natura (50g) foi triturada com 200ml de água, em liquidificador industrial, e filtrada em gaze para extração do meio aquoso, utilizado imediatamente para análise do nitrogênio amoniacal $\left(\mathrm{N}-\mathrm{NH}_{3}\right)$ e do $\mathrm{pH}$. O teor de $\mathrm{N}-\mathrm{NH}_{3}$, como porcentagem do N-total, foi estimado imediatamente, utilizando-se óxido de magnésio e cloreto de cálcio, segundo Official... (1995).
Os teores dos ácidos lático, acético, propiônico e butírico foram quantificados em cromatógrafo a gás, segundo metodologia descrita por Boin (1975).

O delineamento experimental adotado foi $\mathrm{o}$ inteiramente ao acaso, com seis tratamentos e quatro repetições. $\mathrm{O}$ efeito dos níveis de farelo de cacau foi interpretado por meio das análises de variância e de regressão, e a comparação entre os níveis de farelo de cacau e o emurchecimento do capim-elefante foi realizada segundo Dunnett (1955), utilizando-se o Statistical Analyses System (User's..., 1999). 


\section{RESULTADOS E DISCUSSÃO}

$\mathrm{O}$ valor de $\mathrm{pH}$ da silagem produzida com capimelefante e $14 \%$ de farelo de cacau foi similar $(\mathrm{P}>0,05)$ ao da silagem de capim emurchecido (testemunha), mas nos demais níveis de farelo de cacau, os valores de $\mathrm{pH}$ diferiram em relação ao obtido na silagem de capim emurchecido (Tab. 2). $\mathrm{O} \mathrm{pH}$ da silagem sem farelo de cacau $(4,75)$ foi mais alto que $(\mathrm{P}<0,05)$ o da silagem de capim emurchecido $(4,28)$. A silagem produzida com capim emurchecido apresentou maior teor de ácido lático, que, apesar de não-significativo, pode ter contribuído para o maior valor observado nesta silagem.

Embora o valor de $\mathrm{pH}$ da silagem não seja considerado, isoladamente, um bom critério para avaliação da fermentação (Bernardino et al., 2005), uma vez que seu efeito inibitório sobre as bactérias depende da velocidade de redução da umidade do meio, a adição de níveis de farelo de cacau superiores a $14 \%$ contribuiu para valores de $\mathrm{pH}$ mais baixos. Além disso, os teores mais altos de ácido lático nessas silagens podem explicar esses valores mais baixos de $\mathrm{pH}$.

Andrade e Melotti (2004) avaliaram o efeito de alguns tratamentos sobre as características fermentativas da silagem de capim-elefante e observaram, na silagem de capim emurchecido, pH de 4,08, próximo aos valores obtidos neste estudo. As silagens com 21 e $28 \%$ de farelo de cacau apresentaram $\mathrm{pH}$ mais baixo que o da silagem de capim emurchecido. Entre as silagens avaliadas, a de capim-elefante emurchecido e as com 14,21 e $28 \%$ apresentaram $\mathrm{pH}$ na faixa considerada ótima $(3,8$ a 4,2) para a fermentação adequada segundo McDonald et al. (1991).

A adição de farelo de cacau ao capim-elefante afetou significativamente $\mathrm{o} p \mathrm{pH}$ das silagens, promovendo efeito linear decrescente (Fig. 1). Estimado pela equação de regressão, o nível de farelo de cacau a ser adicionado ao capimelefante para produção silagens com $\mathrm{pH}$ na faixa considerada ótima $(3,8-4,2)$ deve ser de 15,5 a $26,9 \%$.

Os teores de carboidratos solúveis $\left(\mathrm{CHO}_{\mathrm{S}}\right)$ nas silagens produzidas com capim-elefante e farelo de cacau diferiram $(\mathrm{P}<0,05)$ dos obtidos na silagem de capim-elefante emurchecido (testemunha). Os carboidratos solúveis são utilizados durante o processo fermentativo para redução do pH e produção de ácido lático; assim, a presença desses carboidratos na silagem indica a presença de açúcar residual, que, em um sistema de alimentação de ruminantes, seria uma fonte de energia prontamente disponível para o animal. No estudo da análise de regressão, detectou-se aumento dos teores de carboidratos solúveis conforme aumentaram os níveis de farelo de cacau ao capim-elefante (Fig. 2). Como o teor de carboidratos solúveis do farelo de cacau foi $10,9 \%$ mais alto que o do capim-elefante, essa diferença pode ser considerada o principal fator para os maiores teores de açúcar residual encontrados nas silagens com farelo de cacau.

Tabela 2. Média de $\mathrm{pH}$ e dos teores de carboidratos solúveis (CHOs), nitrogênio amoniacal $\left(\mathrm{N}_{-} \mathrm{NH}_{3}\right)$ e ácidos lático, acético, propiônico e butírico de silagens de capim-elefante emurchecido (EMUR) e de capim não-emurchecido mais farelo de cacau

\begin{tabular}{|c|c|c|c|c|c|c|c|}
\hline \multirow[t]{2}{*}{ Item } & \multirow{2}{*}{ EMUR } & \multicolumn{5}{|c|}{ Farelo de cacau (\%) } & \multirow{2}{*}{ CV (\%) } \\
\hline & & 0 & 7 & 14 & 21 & 28 & \\
\hline $\mathrm{pH}$ & 4,28 & $4,75^{*}$ & $4,64^{*}$ & 4,12 & $3,89^{*}$ & $3,89^{*}$ & 3,9 \\
\hline $\mathrm{CHOs}^{1}$ & 1,78 & $1,10^{*}$ & $2,21^{*}$ & $3,29^{*}$ & $3,43^{*}$ & $4,03^{*}$ & 6,8 \\
\hline $\mathrm{N}-\mathrm{NH}_{3}{ }^{2}$ & 2,59 & $2,90^{*}$ & $2,78^{*}$ & $2,97^{*}$ & $3,45^{*}$ & $3,85^{*}$ & 7,9 \\
\hline Ácido lático ${ }^{1}$ & 2,49 & 2,23 & 2,48 & 3,14 & 3,49 & 3,47 & 20,2 \\
\hline Ácido acético ${ }^{1}$ & 0,56 & 0,59 & 0,47 & 0,60 & 0,62 & 0,63 & 22,1 \\
\hline Ácido propiônico ${ }^{1}$ & 0,13 & 0,15 & 0,11 & 0,12 & 0,10 & 0,12 & 25,9 \\
\hline Ácido butírico ${ }^{1}$ & 0,21 & 0,23 & 0,16 & 0,14 & 0,16 & 0,16 & 23,5 \\
\hline
\end{tabular}

*Médias seguidas por asterisco diferem da testemunha pelo teste Dunnett $(\mathrm{P}<0,05)$.

CV: coeficiente de variação; ${ }^{1} \%$ da MS; ${ }^{2} \%$ do NT. 


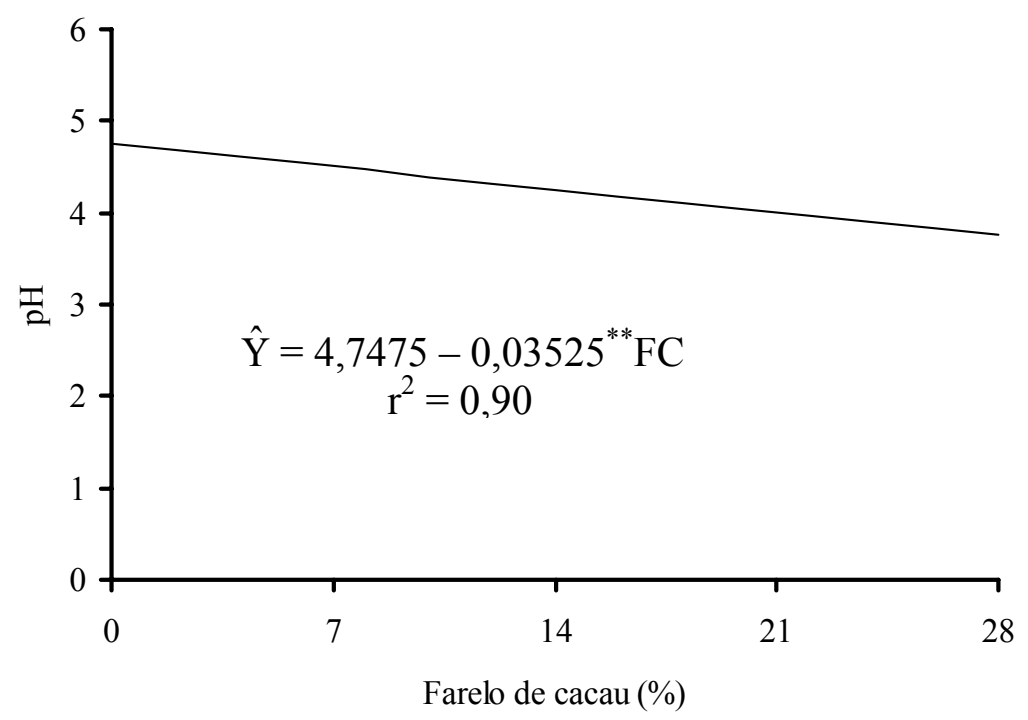

Figura 1. Estimativa dos valores de $\mathrm{pH}$ de silagens de capim-elefante produzidas com diferentes níveis de farelo de cacau ** Significativo a $1 \%$ de probabilidade pelo teste $\mathrm{F}$.

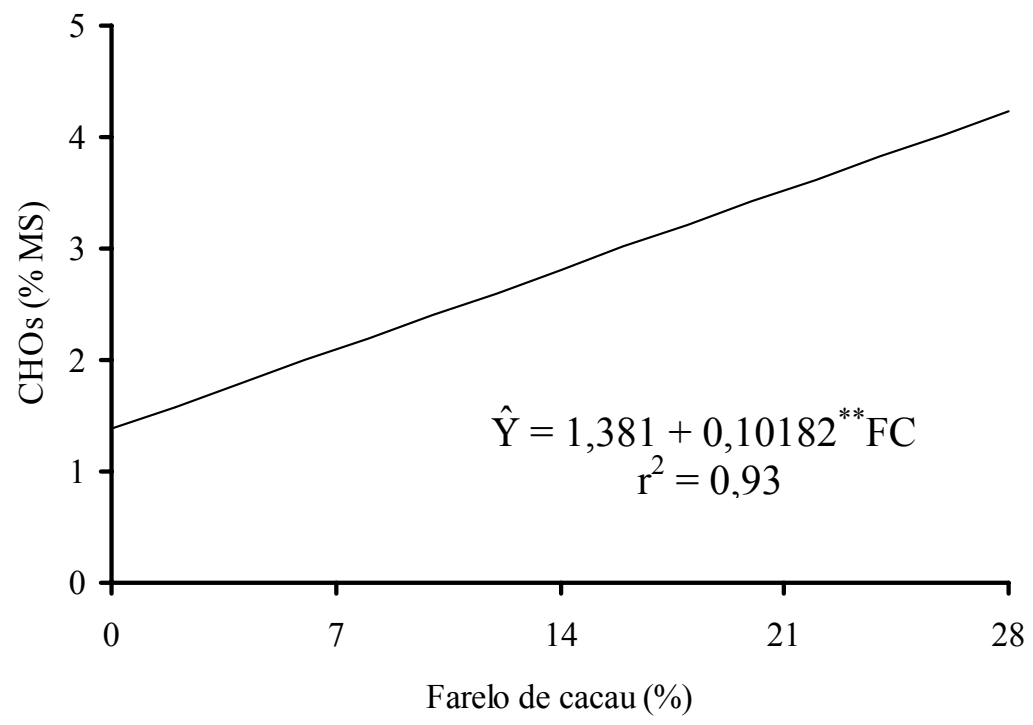

Figura 2. Estimativa dos teores de carboidratos solúveis (CHOs) (base na MS) de silagens de capimelefante produzidas com diferentes níveis de farelo de cacau

** Significativo a $1 \%$ de probabilidade pelo teste F.

Os valores de CHOs presentes na silagem foram bem mais baixos que os observados no material original (capim-elefante e farelo de cacau), o que indica que boa parte dos CHOs foi utilizada pelas bactérias produtoras de ácidos.
Nas silagens produzidas com farelo de cacau e capim-elefante, os teores de nitrogênio amoniacal $\left(\mathrm{N}-\mathrm{NH}_{3}\right)$ foram mais altos $(\mathrm{P}<0,05)$ que o obtido na silagem de capim-elefante emurchecido. Verificou-se efeito quadrático dos níveis de farelo de cacau sobre os teores de $\mathrm{N}$ - 
$\mathrm{NH}_{3}(\mathrm{P}<0,01)$ das silagens, de modo que o valor mínimo de $\mathrm{N}^{-\mathrm{NH}_{3}}(2,83)$ foi observado na silagem com 4,5\% de farelo de cacau (Fig. 3). Resultado semelhante ao de Neiva et al. (1999), que, ao avaliarem o uso de cana-de-açúcar desidratada como aditivo na ensilagem de capimelefante, encontraram $4,5 \%$ de $\mathrm{N}-\mathrm{NH}_{3}$ e menor que o de Silva et al. (2007), que observaram valor de $6,2 \%$ de $\mathrm{N}^{-\mathrm{NH}_{3}}$ em silagem de capimelefante com adição de $20 \%$ de bagaço de mandioca.

Ferreira et al. (2004) avaliaram a adição de bagaço de caju $(0,12,24,36$ e $48 \%)$ na ensilagem de capim-elefante e registraram teores de $\mathrm{N}-\mathrm{NH}_{3}$ de 4,0; 3,5 e 3,1\%, respectivamente, para os níveis de 24,36 e $48 \%$ de bagaço de caju. Os valores obtidos por esses autores foram similares aos encontrados neste experimento nos níveis de 14, 21 e $28 \%$ de farelo de cacau adicionado ao capim-elefante.
Apesar do efeito quadrático dos níveis de farelo de cacau (Fig. 3), de modo geral, os teores de N$\mathrm{NH}_{3}$ das silagens foram baixos, com valor máximo de 3,9\% para o nível de $28 \%$ de adição de farelo de cacau. Os valores obtidos neste trabalho estão na faixa recomendada por Roth e Undersander (1995), que consideraram uma silagem de boa qualidade quando seu teor de N$\mathrm{NH}_{3}$ em relação ao N-total é menor que $5 \%$.

O teor de ácido lático das silagens com farelo de cacau foi similar ao da silagem de capim-elefante emurchecido (Tab. 2). Contudo, o estudo de regressão revelou aumento linear dos teores de ácido lático das silagens conforme aumentaram os níveis de farelo cacau (Fig. 4). Os teores de ácido lático estimados foram, respectivamente, 2,$3 ; 2,6 ; 3,0 ; 3,3$ e 3,7\% nos níveis de $0,7,14,21$ e $28 \%$ de farelo de cacau.

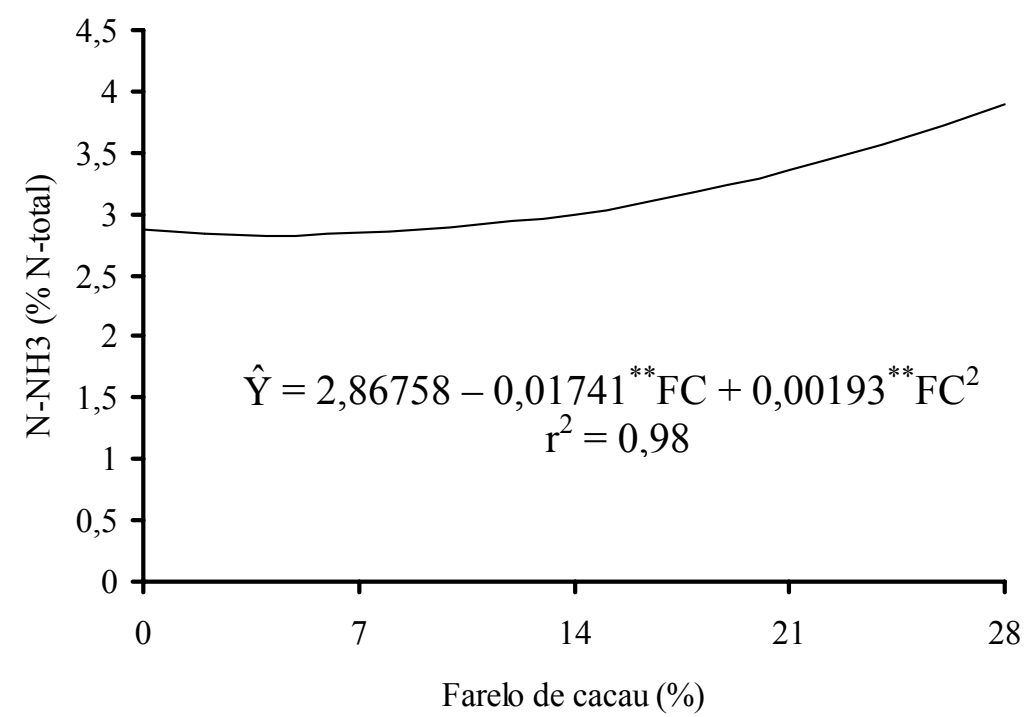

Figura 3. Estimativa dos teores de nitrogênio amoniacal ( $\mathrm{N}-\mathrm{NH}_{3}$ em \% N-total) de silagens de capimelefante produzidas com diferentes níveis de farelo de cacau

** Significativo a $1 \%$ de probabilidade pelo teste $\mathrm{F}$.

Rodrigues et al. (2005) avaliaram a adição de 0; 2,$5 ; 5,0 ; 7,5 ; 10,0 ; 12,5$ e $15,0 \%$ de polpa cítrica na ensilagem de capim-elefante e observaram que a produção máxima de ácido lático foi obtida com $5,8 \%$ de polpa cítrica. Os valores de ácido lático obtidos neste experimento foram menores que os descritos por esses autores, contudo, os valores encontrados nas silagens produzidas com farelo de cacau foram satisfatórios se consideradas as recomendações de Rodriguez et al. (1999). O estádio de maturidade e o tipo de material a ser ensilado, associados ao teor de MS e à presença de $\mathrm{CHO}_{\mathrm{S}}$, são fatores que determinam a extensão da fermentação no interior do silo e a quantidade de ácido lático na silagem. Portanto, essas variações nos teores de ácido lático nos experimentos realizados com forrageiras tropicais são comuns. 


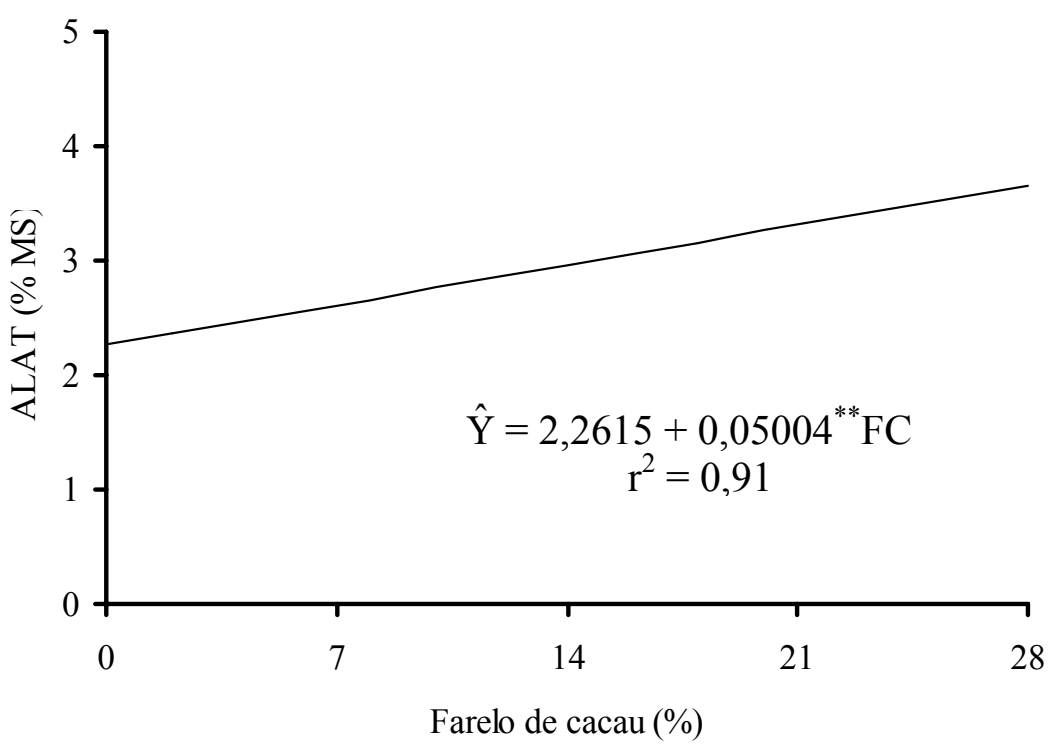

Figura 4. Estimativa dos teores de ácido lático (base na MS) de silagens de capim-elefante produzidas com diferentes níveis de farelo de cacau

** Significativo a $1 \%$ de probabilidade pelo teste $\mathrm{F}$.

Os teores dos ácidos acético, propiônico e butírico das silagens produzidas com farelo de cacau foram similares $(\mathrm{P}>0,05)$ aos encontrados na silagem de capim-elefante emurchecido (Tab. 2). Pela análise de regressão, também não houve efeito significativo de níveis de farelo de cacau sobre as concentrações desses ácidos nas silagens.

De modo geral, em todas as silagens, a concentração dos ácidos acético, propiônico e butírico não prejudicou a estabilidade da silagem. A predominância dos teores de ácido lático possivelmente foi o fator que contribuiu para a obtenção de silagens bem preservadas. Apesar da ausência de diferença significativa, houve variação de até $25 \%$ nos teores de ácido acético entre as silagens. Contudo, todos os valores de ácido acético observados nas silagens foram inferiores ao de $0,8 \%$ relatado por Muck (1988). Níveis de ácido acético superiores indicam alterações indesejáveis durante a fermentação.

Resultados semelhantes aos observados neste experimento para o teor de ácido acético foram anteriormente relatados por Rodrigues et al. (2005), que estudaram a inclusão de polpa cítrica na ensilagem de capim-elefante e registraram teor médio de ácido acético de $0,66 \%$, próximo ao de $0,63 \%$ observado no nível de $28 \%$ de farelo de cacau.

Para o ácido propiônico, as variações foram de 0,10 a $0,15 \%$ e estão de acordo com os valores estabelecidos por Roth e Undersander (1995). Lavezzo et al. (1990) estudaram o efeito do emurchecimento do capim e da adição de formol, ácido fórmico e solução de Viher sobre a qualidade de silagens de capim-elefante, cultivares Mineiro e Vruckwona, e observaram valor médio de ácido propiônico de 0,23\%. Considerando os valores de $\mathrm{pH}$ e $\mathrm{N}_{-} \mathrm{NH}_{3}$ observados neste estudo, pode-se inferir que as silagens foram bem preservadas, uma vez que a concentração de ácido lático nessas foi muito maior que a dos ácidos acético, propiônico e butírico.

Os teores de ácido butírico nas silagens avaliadas, além de não-significativos, também não foram elevados (Tab. 2). Os valores obtidos foram mais baixos que os encontrados por Ferrari Júnior e Lavezzo (2001) em estudo no qual adicionaram bagaço de mandioca na ensilagem de capim-elefante. Possivelmente, o bagaço de mandioca utilizado por esses autores não foi tão eficiente em reduzir a umidade do capim-elefante como o farelo de cacau utilizado neste experimento, o que pode ser comprovado pelos maiores valores de $\mathrm{pH}$ e pelos teores de $\mathrm{N}$ - 
$\mathrm{NH}_{3}$ observados nas silagens produzidas por esses autores.

As baixas concentrações de ácido butírico observadas comprovam que não houve efetivamente fermentação clostrídica e indicam boa qualidade das silagens, uma vez que no material não foi detectada a presença de mofos e/ou bolores.

$\mathrm{Na}$ literatura, observa-se variação entre as concentrações dos ácidos orgânicos em silagens de capim-elefante produzidas com ou sem aditivos (Ferrari Junior e Lavezzo, 2001; Andrade e Melotti, 2004; Rodrigues et al., 2005). Entre outros fatores, essa variação pode ser atribuída ao material utilizado (Pennisetum purpureum, Schum. cv. Napier), à umidade da forragem no momento da ensilagem e ao teor de carboidratos solúveis.

\section{CONCLUSÕES}

O emurchecimento do capim-elefante pela exposição ao sol, apesar de ser inviável em grande escala, possibilitou a produção de silagem com boas características fermentativas. $\mathrm{O}$ uso de farelo de cacau como aditivo na ensilagem de capim-elefante aumentou o teor de ácido lático e favoreceu as características fermentativas da silagem.

\section{REFERÊNCIAS BIBLIOGRÁFICAS}

ANDRADE, S.J.T.; MELOTTI, L. Efeito de alguns tratamentos sobre a qualidade da silagem de capim-elefante cultivar Napier (Pennisetum purpureum, Schum.). Braz. J. Vet. Res. Anim. Sci., v.41, p.409-415, 2004.

BERNARDINO, F.S.; GARCIA, R.; ROCHA, F.C. et al. Produção e características do efluente e composição bromatológica da silagem de capim-elefante contendo diferentes níveis de casca de café. Rev. Bras. Zootec., v.34, p.21852291, 2005.

BOIN, C. Elephant (Napier) grass silage production, effect of addotion on chemical composition, nutritive value and animal performances. 1975. 215f. Tese (Doutorado) Cornell University, Ithaca, NY.

DUNNETT, C.W. A multiple comparison procedure for comparing several treatments with control. J. Am. Stat. Assoc., v.50, p.1096-1121, 1955.

FERRARI JÚNIOR, E.; LAVEZZO, W. Qualidade da silagem de capim-elefante (Pennisetum purpureum, Schum) emurchecido ou acrescido de farelo de mandioca. Rev. Bras. Zootec., v.30, p.1424-1431, 2001.

FERREIRA, A.C.H.; NEIVA, J.N.M.; RODRIGUEZ, N.M. et al. Valor nutritivo das silagens de capim-elefante com diferentes níveis de subprodutos da indústria do suco de caju. Rev. Bras. Zootec., v.33, p.1380-1385, 2004.

HENRIQUE, W.; BOSE, M.L.V. Efeito de aditivos enzimobacterianos sobre a qualidade da silagem de capim-elefante (Pennisetum purpureum, Schum). Rev. Bras. Zootec., v.21, p.429-437, 1992.

LAVEZZO, W.; LAVEZZO, O.E.N.M.; BONASSI, I.A. et al. Efeito do emurchecimento, formol, ácido fórmico e solução de "Viher" sobre a qualidade de silagens de capim-elefante, cultivares Mineiro e Vruckwona. Pesq. Agropecu. Bras., v.25, p.125-134, 1990.

LOPES, R.S.; FONSECA, D.M.; CÓSER, A.C. et al. Avaliação de métodos para estimação da disponibilidade de forragem em pastagem de capim-elefante. Rev. Bras. Zootec., v.29, p.4047, 2000.

McDONALD, P.; HENDERSON, A.R.; HERON, S.J.E. The biochemistry of silage. 2.ed. Marlow: Chalcombe Publications, 1991. 340p.

MUCK, R.E. Factors influencing silage quality and their implications for management. J. Dairy Sci., v.71, p.2992-3002, 1988.

NEIVA, J.N.M.; FERREIRA, A.C.H.; VASCONCELOS, V.R. et al. Use of dehydrated sugar cane (Saccharum officinarum L.) as additive to Napier grass (Pennisetum purpureum Schum) ensilage. In: SILAGE MAKING IN THE TROPICS WITH PARTICULAR EMPHASIS ON SMALLHOLDERS, 161., 1999, Rome. Proceedings... Rome: FAO, 1999. p.167-168.

OFFICIAL methods of analysis. 16.ed. Arlington: AOAC, 1995. v.1.

QUEIROZ FILHO, J.L.; SILVA, D.S.; NASCIMENTO, I.S. Produção de matéria seca e qualidade do capim-elefante (Pennisetum purpureum, Schum.) cultivar roxo em diferentes 
idades de corte. Rev. Bras. Zootec., v.29, p.6974, 2000.

RODRIGUEZ, N.M.; GONÇALVES， L.C.; NOGUEIRA, F.A.S. et al. Silagem de sorgo de porte baixo com diferentes teores de tanino e de umidade no colmo. I - pH e teores de matéria seca e de ácidos graxos durante a fermentação. Arq. Bras. Med. Vet. Zootec., v.51, p.485-490, 1999.

RODRIGUES, P.H.M.; BORGATTI, L.M.O.; GOMES, R.W. et al. Efeito da adição de níveis crescentes de polpa cítrica sobre a qualidade fermentativa e o valor nutritivo da silagem de capim-elefante. Rev. Bras. Zootec., v.34, p.11381145, 2005.

ROTH, G.; UNDERSANDER, D. Silage additives. In: Corn silage production management and feeding. Madison: Madison American Society of Agronomy, 1995. p.27-29.

SILVA, D.J.; QUEIROZ, A.C. Análise de alimentos: métodos químicos e biológicos. Viçosa: UFV, 2002. 235p.
SILVA, F.F.; AGUIAR, M.S.M.A.; VELOSO, C.M. et al. Bagaço de mandioca em ensilagem do capim-elefante: qualidade de silagens e digestibilidade dos nutrientes. Arq. Bras. Med. Vet. Zootec., v.59, p.1719-729, 2007.

SILVA, H.G.O.; PIRES, A.J.V.; SILVA, F.F. et al. Características físico-químicas e custo do leite de cabras alimentadas com farelo de cacau ou torta de dendê. Arq. Bras. Med. Vet. Zootec., v.58, p.116-123, 2006.

SINGH, A.P.; PANDITA, N.N. Effect of urea and molasses on fermentation of Napier silage. Ind. J. Anim. Sci., v.54, p.112-1145, 1984.

SISTEMA brasileiro de classificação de solos. Brasília: EMBRAPA, 1999. 412p.

USER'S guide: statistics. v.8. Cary, NC: SAS Institute, 1999. 295p.

VILELA, D. Aditivos para silagem de plantas de clima tropical. In: REUNIÃO ANUAL DA SOCIEDADE BRASILEIRA DE ZOOTECNIA, 35., 1998, Botucatu. Anais... Botucatu: Sociedade Brasileira de Zootecnia, 1998. p.73111. 